\title{
11 \\ Learning Portfolios: Creative Connections Between Formal and Informal Learning
}

\author{
Alice Cassidy \\ University of British Columbia
}

How do you know what students in your course "took away" with them? Why not ask? Through a learning portfolio assignment, I invited students to show: how they met the course objectives; connections they made to other courses as well as aspects of their lives; and their views and perspectives about the course material and processes. They were asked to include tangible evidence, examples, connections, and reflections from all class sessions, discussions, and other assignments. They were also required to express themselves through a creative variety of styles and formats, including a concept map and a world map. What were their reactions to the assignment? Many noted that it encouraged them to think critically and that it was a fun way to show the links between the course and their own lives. Might you like to use or adapt some or all parts of my learning portfolio assignment in a course (any discipline) that you teach? Through reading this paper and trying the described activities, you will have completed your own mini-learning portfolio and explored methods of assessment. ${ }^{1}$

It is a miracle that curiosity survives formal education.

- Albert Einstein

\section{Introduction}

$I^{2}$ became interested in the use of learning portfolios through several experiences related to connecting formal and informal learning. I learned many of the important skills I use today through informal, everyday practice and application (Cassidy, 2006a,
2007). Students I have interviewed feel that postsecondary institutions need to acknowledge the learning that takes place outside of credit courses (Cassidy, 2006b). I love teaching and have designed and taught both credit courses at the University of

\footnotetext{
${ }^{1}$ If you are interested in templates and resources for use in your own courses, feel free to contact me at alice.cassidy@ubc.ca 
British Columbia as well as many non-credit short lecture and field-based courses that people take for the love of the topic, with no grades or assignments. Hence, the mix of informal and formal learning has been very important to me both as a learner and as a teacher, and inspired me to offer these opportunities to my students as well.

In a course I taught for 14 years, I experimented with different kinds of assignments and inclass activities, sought student input through alumni advising teams, and in the last eight years of this course, assigned students a learning portfolio in lieu of a final exam. I share the templates I designed, and other aspects of this assignment with you so that you may use or adapt it for your own use.

\section{What is a Learning Portfolio?}

A learning portfolio is a collection of one's work, often customized to show evidence of meeting particular goals or specific areas of development, learning, and growth. Learning portfolios can appear in hard copy or electronically. Some related terms include course portfolios (e.g., University of Nebraska Lincoln, 2009), professional portfolios (Bossers, Kernaghan, Hodgins, O’Connor, \& Van Kessel, 1999), and experiential learning portfolios (Brown, 2002), all of which have been used, across disciplines, in a variety of contexts including K-12, post-secondary, and professional programs.

Learning portfolios have many valuable outcomes. Herring, Hibbs, Morgan, and Notar (2007) describe how student success and motivation for learning increase through the use of standards-based digital portfolios. Brown's (2002) findings suggest that the development of a portfolio increases students' understanding of "what, why, and how they learned" (p. 228), enhances their communication and organization skills, and reinforces the importance of reflection in learning. In my course, I introduce the learning portfolio assignment with the following definition (Cassidy, 2008):

Your personal version of the course, documenting your learning throughout the term (and briefly, what you will take away with you), and presented in creative, varied, and multi-linked ways that include tangible evidence, examples, connections and reflections, based on three key criteria.

\section{Learning Portfolio Use in My Course}

In my course, the learning portfolio assignment contributes to $35 \%$ of the final grade, with a one-page check-in assignment, worth $7 \%$, handed in half-way through the term to provide formative feedback, and a 10 -page final learning portfolio, worth $28 \%$, due on the last day of term. In-class activities allow students to practise the kinds of mapping and charting expected in the learning portfolio.

To better explain how this (somewhat) complicated assignment works in my course, I modeled it below, and I invite you to try it out as if you were a student in my course. To make it most helpful to you, I have adapted the topic and simplified the tasks.

\section{Your Mini Learning Portfolio Assignment}

Topic: Getting the most out of the next conference you attend

Part 1: Setting two of your own goals/objectives

What is the next conference you are planning to attend? Think about why you registered for and are attending it. What do you hope to achieve, or get out of it? It costs money and your valuable time. How do you hope to make that time and money well spent, for you personally and/or professionally?

Your two goals/objectives will be the basis for your mini learning portfolio project. You will need one blank sheet of paper. I suggest you fold your sheet in half, lengthways, so that you have a long writing space with room for columns. Write your first Goal/Objective on the left side, in the top 'half', and other one in the lower 'half', also on the left. You will be adding more columns. Having described this suggested format, if you 
prefer to go 'free-form', this can work too.

Here are a few examples that you might borrow, build upon, or be inspired by to write your own. Aim for two Goals/Objectives for now; you might have more that you can add later:

- Collect new ideas and strategies by attending sessions on topics related to my key area of practice.

- Be actively engaged in teaching and learning techniques by choosing sessions that are described as such (and hope they do what they say).

- Increase my network of colleagues by meeting as many people as I can during all parts of the conference.

\section{Part 2: Other sections to add}

You may wish to add column for each section, or create it in more of a free-form diagram:

- Sessions to attend (sub-heading: topics, facilitators, or what institution from).

- Notes to self during unstructured time (sub-heading: receptions, breaks, banquet, other).

- My area/topics of work/study/other (optional: what you really want! e.g. attend a session just because it looks enjoyable).

- 'Wild card' - an extra section for whatever comes up. You might know what other section(s) you need, you might not know yet, or you might not need any more

You have just created your own version of what I give my students. Though, there are differences: in my course, I state the objectives in the syllabus; I give students some suggested titles for columns that I think would help them meet the three criteria for the assignment; I email the students a template chart that they can use as is, or adapt as they wish; and in-class activities and discussions focus on these very aspects, so that students are able to work on their learning portfolio during class time, to ask questions and to receive feedback.

\section{Concept Maps as a Visual Tool}

You can also organize the chart you have just created using concept maps. Instructions on how you can try to create a concept map, using a familiar example, are listed below:

- You will need a blank piece of paper.

- Print the key term 'house' in the middle of the map and circle it.

- Identify certain parts of a house (e.g., room, kitchen, roof, garden, or front door). Each of these is a new term. Circle each term you add. (If you stop now, many would call what you have a mind map.)

- Draw an arrow between related terms, and note, above or beneath each arrow, what the connection is. The arrow may move in one or both directions.

- Add more explanatory arrows as needed to describe, as best as you can, how all the terms you have added are related.

You have just drawn a simple concept map, showing key terms and how they are interconnected. If you were to show the concept map you just created to a colleague who did the same thing, how similar do you think they would be? Concept maps are thought to be powerful learning tools. They closely mirror the process of "thinking and learning" (Cassidy, $\mathrm{Na}$ konechny, \& Griffiths, 2001). Because of this, it is a skill that is transferable to any situation where the creative processing of ideas is required. As you know, in any complex situation there is usually not one correct answer. Hence, concept maps can be very unique. There are also many ways to create them, including as a flow chart from the top down, or as a tree from the roots up, or, as we did just now, starting in the centre and radiating out.

In Figure 1 (an example from my course, with permission to use granted by the student who 
created it), humans are at the centre of the concept map, with connections, explained on the arrows, to various topics explored during the course. Some connecting topics, such as community service-learning, in the bottom left, and the subtopic, biodiversity, in the top left, are then depicted using their own unique cycles of terms and arrows.

In my course, students create concept maps as part of their 10-page learning portfolio assignments. They also include word-image diagrams, world maps, and a variety of other methods to synthesize a large amount of material and make connections as described by the assignment criteria. Figures 2 and 3 (with permission to use granted by the students who created them) show two such examples, including a leaf metaphor and a Venn diagram.

Start a concept map for yourself, based on the writing in your chart from above. I invite you to keep adding to your concept map and/or your chart.

\section{Assessing Learning Portfolios}

I designed a checklist rubric, in the form of a chart, to assess my students' learning portfolios. Each row on the chart represented an individual student. Columns represent each of the three main criteria (coverage, links, and variety of styles) for the assignment, which are worth approximately $33 \%$ each. I subdivide "coverage" into columns for each of the classes' topics. As I review each portfolio, I could check off whether it was there or not, and note with an asterisks where the level of work was particularly high; by drawing lines between cells, I could also indicate the links students made. Using this technique, I could review and compare how well each student met the

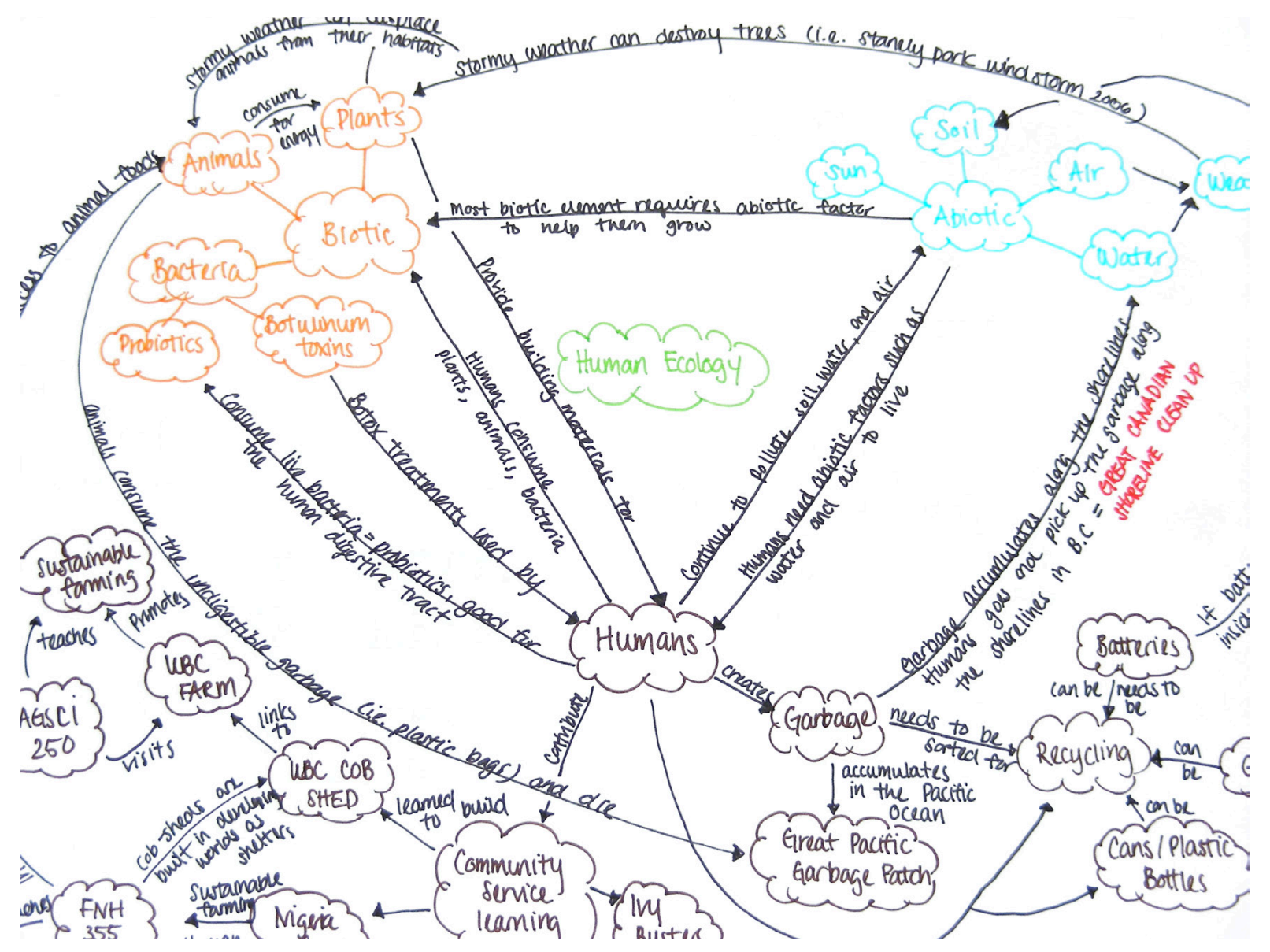

Figure 1

Example of a Concept Map 


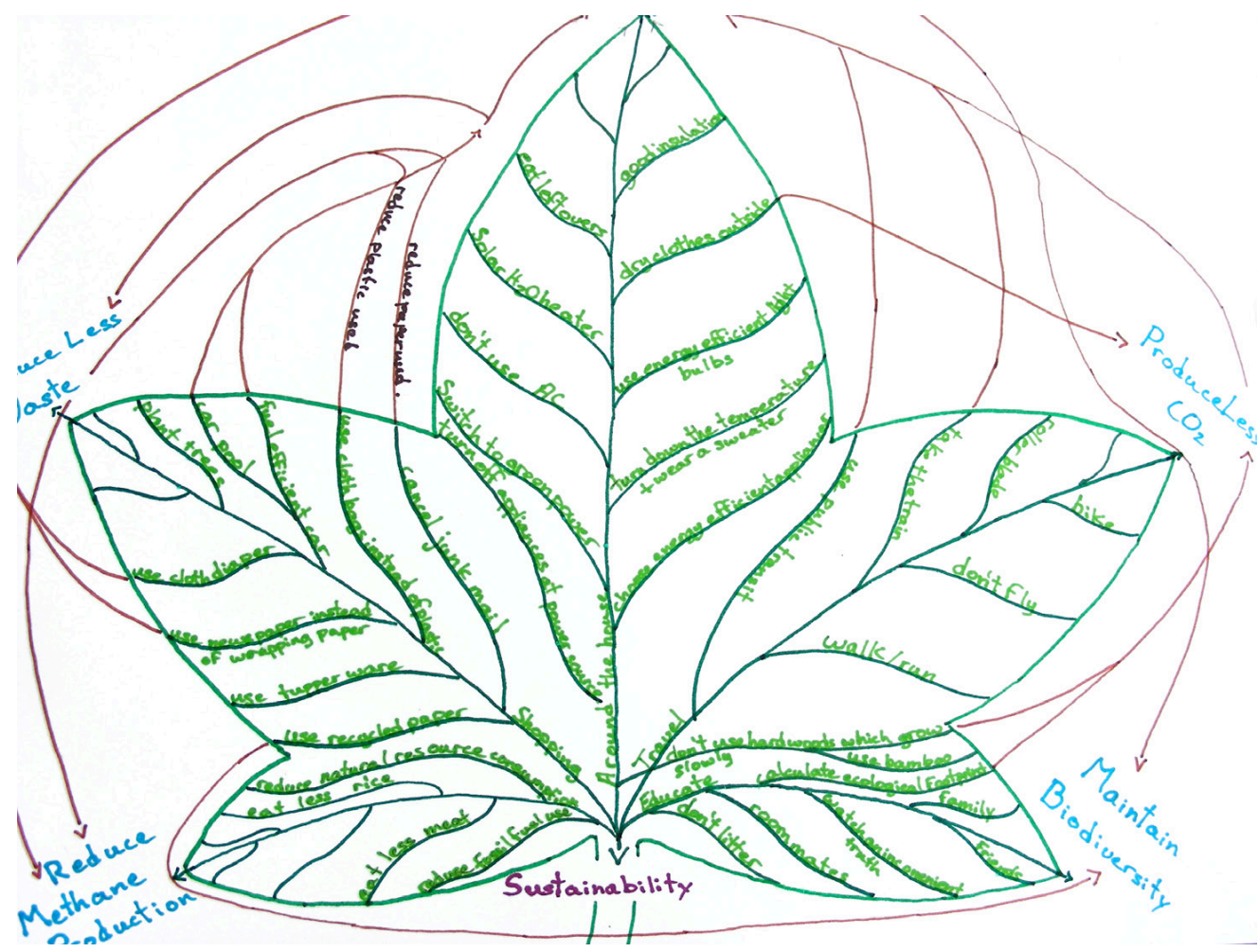

Figure 2

Example of a Word Diagram Using a Leaf Metaphor

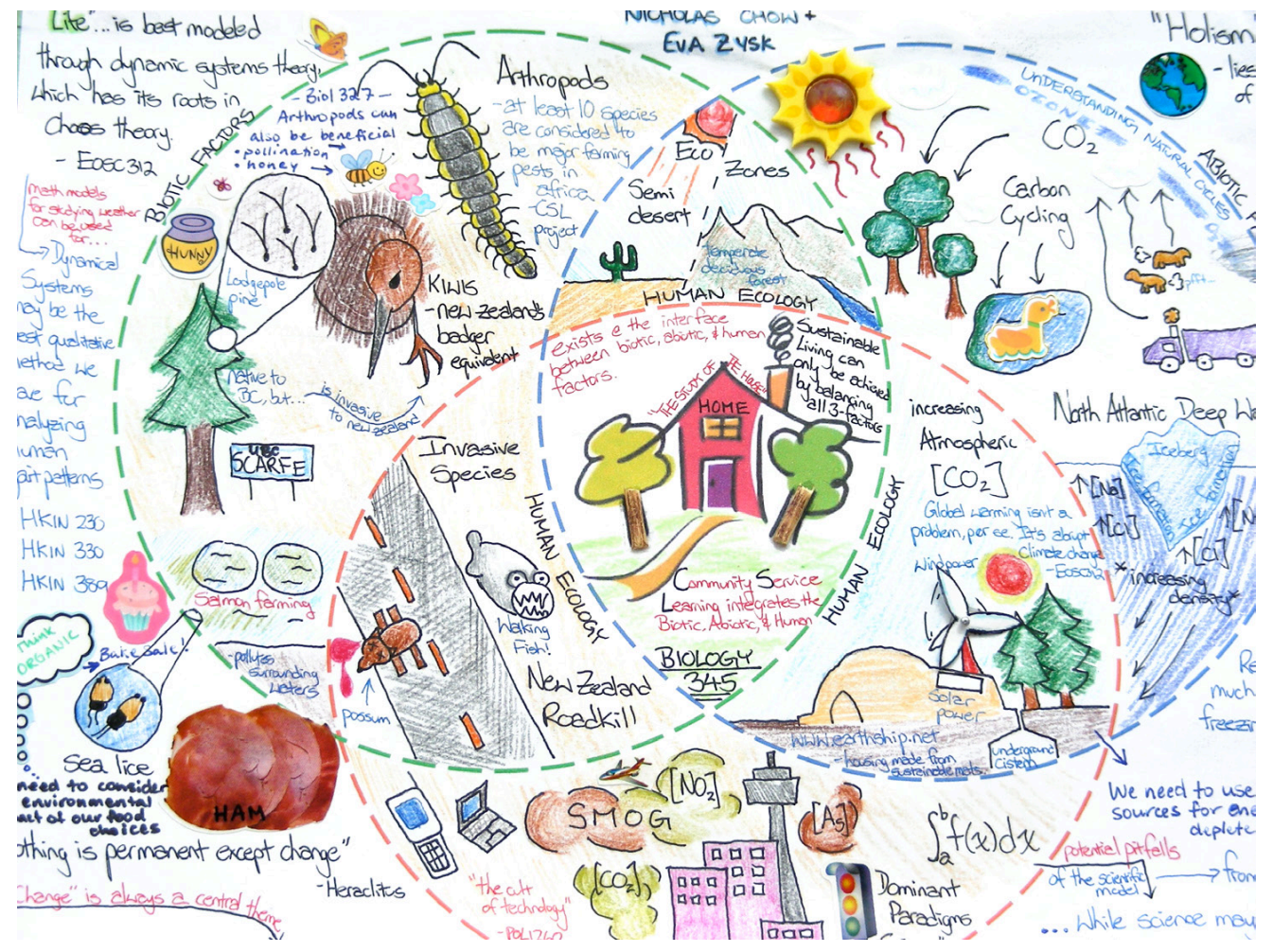

Figure 3

Example of a Venn Diagram 
criteria for the assignment, and determine the final mark. The overall mark for this assignment is not derived simply by adding up the columns. The concept, the "whole is greater than the sum of the parts," applies here. Giving students a lot of informal and formal feedback throughout the term was essential.

I assess the mid-term check-in (one page of the learning portfolio) similarly, in order to give students an idea of what they are doing well and how they could improve for the final assignment. In past years, I invited students to practise self and peerassessment during class time. This technique might work well for summative assessment in large classes.

Barrett (2007) underscores the need to pay particular attention to the difference between assessment for learning and assessment of learning. Though concept maps and learning portfolios, at a glance, may seem challenging to assess, I found that the key is to break them down into the criteria you set for your students, then methodically go through each one in turn. You may find that the whole is greater than the sum of the parts and need to find a way to acknowledge extra effort or holistic value as well. Other examples of assessment techniques can be found in such works as Stoddart, Abrams, Gasper, and Canaday (2000), and Nicoll, Francisco, and Nakhleh (2001).

\section{Concluding Remarks}

From eight years of inviting my students to create learning portfolios as a final course assignment, I found that they valued the experience very much the creativity of it; the way it valued not only how they showed their understanding of key concepts of the course, but how it valued connections they made between courses, or other formal and informal learning experiences; and other aspects of their lives. I wonder if, as educators, we sometimes lose track of the tension that students can feel between their everyday lived experience and academic courses, and the disconnect they feel moving from course to course. It is my hope that asking students to identify these very connections in their learning portfolios facilitates students' understanding of the place of the course within their lives. I invite you to try using this approach and, upon request by email, will happily send you templates and other material I used so that you can use or adapt it for your own teaching context.

\section{References}

Barrett, H.C. (2007). Researching electronic portfolios and learner engagement: The REFLECT initiative. Journal of Adolescent \& Adult Literacy, 50(6), 436-449.

Bossers, A., Kernaghan, J., Hodgins, L., O’Connor, C., \& Van Kessel, M. (1999). Defining and developing professionalism. Canadian Journal of Occupational Therapy, 66, 116-121.

Brown, J.O. (2002). Know thyself: The impact of portfolio development on adult learning. Adult Education Quarterly, 52(3), 228-245.

Cassidy, A., Nakonechny, J., \& Griffiths, T. (2001). Concept mapping: Mirroring processes of thinking and learning. Tapestry, 4. Centre for Teaching and Academic Growth, University of British Columbia, Vancouver, BC.

Cassidy, A. (2006a). Guide to this issue: The times, ways and places where we learn best: As unique and diverse as we can imagine. Tapestry, 13. Centre for Teaching and Academic Growth, University of British Columbia, Vancouver, BC.

Cassidy, A. (2006b). Spotlight: The role of student governance in teaching and learning. Tapestry, 13. Centre for Teaching and Academic Growth, University of British Columbia, Vancouver, BC.

Cassidy, A. (2007). Learning: The times, the ways, and the places. Teaching Professor. Madison, WI: Magna Publishing.

Cassidy, A. (2008). Biology 345: Human Ecology. 
Course Syllabus, Zoology Department, Faculty of Science, University of British Columbia, Vancouver, BC.

Herring, D., Hibbs, R., Morgan, B. \& Notar, C. (2007). Show what you know: ePortfolios for 21st century learners. In R. Carlsen, K. McFerrin, J. Price, R. Weber, \& D.Willis. (Eds.), Proceedings of the Society for Information Technology and Teacher Education International Conference (pp. 86-92). Chesapeake, VA: AACE.

Nicoll, G., Francisco, J., \& Nakhleh, M. (2001). A three-tier system for assessing concept map links: A methodological study. International Journal of Science Education, 23(8), 863-875.

Stoddart, T., Abrams, R., Gasper E., \& Canaday, D. (2000). Concept maps as assessment in science inquiry learning: A report of methodology. International Journal of Science Education 22(12), 1221-1246.

University of Nebraska Lincoln. (2009). Course portfolio examples and overviews. Retrieved from http://www.courseportfolio.org/peer/pages/ index.jsp?what=rootMenuD\&rootMen $\mathrm{uId}=6$

\section{Biography}

Alice Cassidy, Ph.D., is Associate Director of the Centre for Teaching and Academic Growth (TAG) and Leader of the Institute for the Scholarship of Teaching and Learning at the University of British Columbia. A biologist by academic training, her work focuses on active teaching and learning. She most enjoys designing learning activities that trigger the curiosity and creativity that dwells inside each of us. 